\title{
Why an M1 Antagonist Could Be a More Selective Model for Memory Impairment than Scopolamine
}

\author{
Arjan Blokland*, Anke Sambeth, Jos Prickaerts and Wim J. Riedel \\ Maastricht University, Maastricht, Netherlands
}

Keywords: actelylcholine, Alzheimer, cognition enhancer, memory, deficit model

Since the early studies of Deutsch (1), the non-selective muscarinic receptor antagonist scopolamine has been used as a drug that impairs memory performance in man. The notion that scopolamine could be used as a pharmacological model of age-associated memory impairment and dementia further strengthened the cholinergic hypothesis of geriatric memory dysfunction by Bartus et al. (2). Since then, a vast amount of studies applied this model to induce memory impairments in young healthy subjects to model age-related memory disorders. At present, scopolamine is still considered to be the best model for inducing cognitive impairments in healthy subjects (3). Scopolamine is therefore used as a pharmacological model to test novel cognition-enhancing drugs in animals [e.g., Ref. (4-6)] and in humans [e.g., Ref. $(7,8)]$. In clinical trials, scopolamine is in particular being used as a model for $\mathrm{AD}$ in which novel cognition-enhancing drugs are tested (see https://ClinicalTrials.gov).

Further efforts have been made to compare human and animal data with scopolamine to further validate the scopolamine as a model of cognitive impairments. For example, comparable tests were developed for humans and animals to allow cross-species comparison [e.g., Ref. $(9,10)]$. Another effort is comparing scopolamine effects on brain imaging parameters $(11,12)$. These studies reveal great cross-species similarities in the effects of scopolamine in comparable cognitive tasks in humans and animals, and that the effects on central blood flow is also comparable. These studies have resulted in a huge database in which the effects of scopolamine on cognitive and non-cognitive functions have been documented. This also relates to doses and routes of administration. Furthermore, interactions with various other drugs (also non-cholinergic) have been documented, which supports the notion of drug interactions in memory functions. Taken together, scopolamine is considered as a golden standard for cholinergic deficits and the existing data were used as a reference for evaluating novel cognition-enhancing drugs.

Although scopolamine has this established (gold standard) status, there are also some important issues related with this drug. A first point is that scopolamine is binding to both peripheral and central muscarinic receptors [see Ref. (13)]. Thus, scopolamine binds to all five different muscarinic receptors which are located in the brain as well in the peripheral system. This may relate to the various side effects that can occur after administration of scopolamine. Typical side effects are: dry mouth or throat, dizziness, drowsiness, fatigue, nausea, light-headedness, and blurred vision [e.g., Ref. (9)]. A careful analytic review on the effects of scopolamine in animals has shown that scopolamine at low doses mainly affects attentional functions and that memory performance is only affected at higher doses [see Ref. (13)]. Moreover, at relative low doses, typical side effects (increased omissions and latencies in responding) can be observed in rodents that may have an impact on performance in memory tasks.

In humans, similar effects on sedation have been observed, but it has been suggested that these effects could be dissociated from the effects on memory impairments [see Ref. (14)]. Interestingly, these effects seem to be dependent on the route of administration. Thus, intramuscular or intravenous administration has shown robust effects on memory performance (3), accompanied with 
sedative effects. However, oral administration of scopolamine has resulted in sedative effects but in the absence of memory impairments $(15,16)$. Interestingly, the effects of intranasal scopolamine have also been investigated on side effects and cognitive performance $(17,18)$. This generally leads to a faster brain penetration and may have a stronger effect on brain function. Notably, no effects were found on cognition, and only some side effects were reported. However, it could be argued that the dose was too low $(0.4 \mathrm{mg})$ or brain penetration was too fast in order to affect cognitive performance. Unfortunately, no plasma concentrations can be measured after intranasal administration, which makes it difficult comparing this with other routes of administration. Apparently, the effects of scopolamine on sedation are found in most clinical studies, whereas the effects on cognition are reported in fewer studies. Some experimental studies explicitly investigated the relation between sedation and cognition by comparing the effects of scopolamine and benzodiazepines $\left(\mathrm{GABA}_{\mathrm{A}}\right.$ agonist). In one study, the effects of scopolamine and lorazepam on cognition and sedation could not be separated (19). However, the effect of scopolamine and lorazepam can be separated on encoding processes, as shown in a repetitive priming paradigm (20). Another study also showed a differential effect of lorazepam and scopolamine on attention and working memory (21). Thus, the effects of benzodiazepines and scopolamine on arousal may be similar, but the effects on cognitive functions can be differentiated if specific tasks are used.

A subsequent study was able to show a one-sided dissociation between sedation and cognitive impairment (22). In this study, the effects of an $\mathrm{H} 1$ receptor antagonist (diphenhydramine) were compared with lorazepam and scopolamine. All drugs affected arousal but only scopolamine and lorazepam impaired memory. These findings were supported by the drug effects on EEG measures and indicate that the effects on arousal and memory were not interdependent. Although different studies suggest a differentiation between drug effects on arousal and memory $(19,22)$, a drug that only impairs cognitive functions and not the arousal state would be preferable. Moreover, this would show a double dissociation between arousal and memory performance (22).

Although the literature has shown robust effects of scopolamine on word learning (episodic memory task), some reported findings may suggest something else. Thus, scopolamine had a larger effect on immediate and delayed recall when presentation rate was fast (i.e., 1 word per $2 \mathrm{~s}$ ), whereas it had only a marginal effect when presentation rate was 1 word per $5 \mathrm{~s}$ (23). The effects of scopolamine on word learning seem to be dependent on the pace of the task, which is related to the presentation time, inter-stimulus interval, and response-stimulus interval. These parameters are of key importance, whether attentional circuits in the brain are triggered. The faster the pace, the more declarative memory performance will become dependent on attentional constraints [or in essence, time constraints; see Ref. (24)]. Taken together, these findings suggest that the separation between arousal/attention and memory effects may not be easy to establish and require more variation of experimental parameters before this can be demonstrated.

As mentioned earlier, scopolamine is assumed to model the impaired cholinergic neurotransmission in AD. However, more recent studies have also shown other characteristic features of brain dysfunction in $\mathrm{AD}$ and the scopolamine model. For example, arterial spin labeled perfusion MRI studies have shown hypoperfusion mainly in the temporal lobe regions of $\mathrm{AD}$ patients $(25,26)$. In contrast, scopolamine has been found to mainly reduce cerebral blood flow in frontal areas (27-29). Although it may be questioned to what extend reduced blood flow in specific brain regions may relate to specific cognitive functions, these data do not support a strong face/predictive validity for scopolamine with respect to brain blood flow and the site of action in the brain. Although the above may caution the use of scopolamine as a model for memory impairment, scopolamine still is the golden standard for this purpose. The main advantage is that this drug is well characterized and there is enormous database to which the effects with new treatments can be compared with. For these reasons, it is obvious that scopolamine still will be used as a drug to induce memory impairments in animals and humans to model aging/AD-related memory dysfunctions.

Interestingly, a more specific cholinergic memory deficit model has been proposed based on selectivity of muscarinic receptors. Both the $\mathrm{M} 1$ and $\mathrm{M} 2$ receptors have been indicated as relevant for cognition, but most research has focused on the M1 receptor (30). It has been shown that the M1 receptor is more specifically located in cortical and hippocampal structures and that its expression in the body is limited [see Ref. (13)]. Moreover, the M1 receptor has been indicated to be related to cognitive deficits in $\mathrm{AD}(31,32)$. Therefore, it has been suggested that blocking the M1 receptor could be regarded as a better model for age-associated and dementia-related memory deficits $(13,33)$. Biperiden, which is clinically used to reduce motor symptoms in Parkinson's disease, is a relative selective muscarinic type 1 (M1) antagonist (34), and could be used as a drug to evaluate the effects on memory. Two human studies have shown selective effects of biperiden treatment on memory performance with only limited side effects $(35,36)$. A noteworthy feature of the postsynaptic $\mathrm{M} 1$ receptor is that an antagonist can impair memory performance and that an agonist can improve performance. Thus, the $\mathrm{M} 1$ receptor is also considered as a target to improve memory functions $(37,38)$. Various M1 agonists have been developed as drugs to improve memory performance in dementia and schizophrenia (39). One of the first (orthosteric) M1 agonist that showed efficacy in Alzheimer patients and schizophrenics was xanomeline $(40,41)$. However, this drug was not very selective for the M1 receptor and associated with doselimiting side effects and was therefore not further developed. More recently, positive allosteric modulators (PAMs) have been developed which are more selective for the M1 receptor. One study in monkeys showed that an M1 positive allosteric modulator (PAM) improved the performance in an object detour test (42). Another study in humans showed that a PAM of the M1 receptor improved memory functions in a nicotine abstinence model (43). Taken together, the M1 receptor can be regarded as an interesting specific target for memory modulation.

The main mechanism by which M1 receptors can impair or improve memory is obviously via the cholinergic neurotransmission. However, additional mechanisms of action of M1 receptors have been described. For example, an in vitro study showed 
that blocking the M1 receptor decreases dendritic long-term potentiation (LTP) in the CA1 region of the hippocampus (44). Conversely, activation of the M1 receptors enhances LTP in the hippocampus (45). These effects are mediated by a co-localization of M1 and NMDA receptors and that activation of M1 receptors leads to enhanced NMDA receptor currents (46). This bidirectional modulation of LTP by M1 receptor modulation supports the notion that, aside from a cholinergic mechanism, LTP is also involved in the modulating the memory effects. It should be noted that the M1 receptor is also located in medium spiny neurons, where they are involved in neuronal plasticity and involved in motor functions (47). There are also studies showing that blocking the M1 receptors may affect more complex motor behavior [e.g., Ref. $(48,49)$ ]. Actually, the M1 receptor antagonist biperiden was developed for this purpose. Although modulation of the M1 receptor in this structure may contribute to the behavioral effects of drugs that affect this receptor, it has been shown that the strongest effects of allosteric agonist were most pronounced in the hippocampus and to a lesser extend in the striatum (50). This

\section{REFERENCES}

1. Deutsch JA. The cholinergic synapse and the site of memory. Science (1971) 174:788-94. doi:10.1126/science.174.4011.788

2. Bartus RT, Dean RL, Beer B, Lippa AS. The cholinergic hypothesis of geriatric memory dysfunction. Science (1982) 217:408-17. doi:10.1126/science. 7046051

3. Ebert U, Kirch W. Scopolamine model of dementia: electroencephalogram findings and cognitive performance. Eur JClin Invest (1998) 28:944-9. doi:10.1046/j.1365-2362.1998.00393.x

4. Lange-Asschenfeldt C, Schäble S, Suvorava T, Fahimi EG, Bisha M, Stermann T, et al. Effects of varenicline on alpha4-containing nicotinic acetylcholine receptor expression and cognitive performance in mice. Neuropharmacology (2016) 107:100-10. doi:10.1016/j.neuropharm.2016.03.025

5. Park HR, Lee H, Park H, Cho WK, Ma JY. Fermented sipjeondaebo-tang alleviates memory deficits and loss of hippocampal neurogenesis in scopolamine-induced amnesia in mice. Sci Rep (2016) 6:22405. doi:10.1038/ srep22405

6. Buccafusco JJ. The revival of scopolamine reversal for the assessment of cognition-enhancing drugs. In: Buccafusco JJ, editor. Methods of Behavior Analysis in Neuroscience. Boca Raton, FL: CRC Press/Taylor \& Francis (2009).

7. Newhouse P, Albert K, Astur R, Johnson J, Naylor M, Dumas J. Tamoxifen improves cholinergically modulated cognitive performance in postmenopausal women. Neuropsychopharmacology (2013) 38:2632-43. doi:10.1038/ npp. 2013.172

8. Lenz RA, Baker JD, Locke C, Rueter LE, Mohler EG, Wesnes K, et al. The scopolamine model as a pharmacodynamic marker in early drug development. Psychopharmacology (Berl) (2012) 220:97-107. doi:10.1007/ s00213-011-2456-4

9. Harel BT, Pietrzak RH, Snyder PJ, Maruff P. Effect of cholinergic neurotransmission modulation on visual spatial paired associate learning in healthy human adults. Psychopharmacology (Berl) (2013) 228:673-83. doi:10.1007/ s00213-013-3072-2

10. Talpos JC, Aerts N, Fellini L, Steckler T. A touch-screen based paired-associates learning (PAL) task for the rat may provide a translatable pharmacological model of human cognitive impairment. Pharmacol Biochem Behav (2014) 122:97-106. doi:10.1016/j.pbb.2014.03.014

11. Ahnaou A, Huysmans H, Jacobs T, Drinkenburg WH. Cortical EEG oscillations and network connectivity as efficacy indices for assessing drugs with cognition enhancing potential. Neuropharmacology (2014) 86:362-77. doi:10.1016/j.neuropharm.2014.08.015

12. Hegedűs N, Laszy J, Gyertyán I, Kocsis P, Gajári D, Dávid S, et al. Scopolamine provocation-based pharmacological MRI model for testing procognitive agents. J Psychopharmacol (2015) 29:447-55. doi:10.1177/0269881114565652 may suggest that M1 drugs predominantly affect hippocampalrelated functions. Along this line, the prescription of biperiden reports that amongst its side effects is memory loss. Moreover, this may further support the use of M1 antagonists as a model for selective memory impairment.

In summary, although scopolamine is being used to induce memory impairments in human subjects some aspects of this drug may caution the use of this drug to specifically impair memory performance. M1 antagonism can impair memory more specifically and M1 agonism (more specifically, PAMs) can improve memory. This strongly supports the notion that the M1 receptor is highly relevant and specific for memory. The use of M1 antagonist may offer a good alternative but more data are needed to support this claim.

\section{AUTHOR CONTRIBUTIONS}

AB wrote the paper. AS, JP, and WR commented on earlier versions of the manuscript.

13. Klinkenberg I, Blokland A. The validity of scopolamine as a pharmacological model for cognitive impairment: a review of animal behavioral studies. Neurosci Biobehav Rev (2010) 34:1307-50. doi:10.1016/j.neubiorev.2010.04.001

14. Liem-Moolenaar M, de Boer P, Timmers M, Schoemaker RC, van Hasselt JG, Schmidt S, et al. Pharmacokinetic-pharmacodynamic relationships of central nervous system effects of scopolamine in healthy subjects. Br J Clin Pharmacol (2011) 71:886-98. doi:10.1111/j.1365-2125.2011.03936.x

15. Rusted JM. Dissociative effects of scopolamine on working memory in healthy young volunteers. Psychopharmacology (Berl) (1988) 96:487-92. doi:10.1007/ BF02180029

16. van Ruitenbeek P, Vermeeren A, Riedel W. Histamine H1-receptor blockade in humans affects psychomotor performance but not memory. J Psychopharmacol (2008) 22:663-72. doi:10.1177/0269881107081526

17. Weerts AP, Pattyn N, Putcha L, Hoag SW, Van Ombergen A, Hallgren E, et al. Restricted sedation and absence of cognitive impairments after administration of intranasal scopolamine. J Psychopharmacol (2015) 29:1231-5. doi:10.1177/0269881115598414

18. Simmons RG, Phillips JB, Lojewski RA, Wang Z, Boyd JL, Putcha L. The efficacy of low-dose intranasal scopolamine for motion sickness. Aviat Space Environ Med (2010) 81:405-12. doi:10.3357/ASEM.2668.2010

19. Curran HV, Schifano F, Lader M. Models of memory dysfunction? A comparison of the effects of scopolamine and lorazepam on memory, psychomotor performance and mood. Psychopharmacology (Berl) (1991) 103:83-90. doi:10.1007/BF02244079

20. Thiel CM, Henson RN, Dolan RJ. Scopolamine but not lorazepam modulates face repetition priming: a psychopharmacological fMRI study. Neuropsychopharmacology (2002) 27:282-92. doi:10.1016/S0893-133X(02) 00316-0

21. Mintzer MZ, Griffiths RR. Lorazepam and scopolamine: a single-dose comparison of effects on human memory and attentional processes. Exp Clin Psychopharmacol (2003) 11:56-72. doi:10.1037/1064-1297.11.1.56

22. Curran HV, Pooviboonsuk P, Dalton JA, Lader MH. Differentiating the effects of centrally acting drugs on arousal and memory: an event-related potential study of scopolamine, lorazepam and diphenhydramine. Psychopharmacology (1998) 135:27-36. doi:10.1007/s002130050482

23. Awipi T, Deptula D, Riedel WJ. A comparison of two cognitive batteries for pharmacological testing. Soc Neurosci Meet Abstr (2011) 878.17.

24. Riedel WJ, Blokland A. Declarative memory. Handb Exp Pharmacol (2015) 228:215-36. doi:10.1007/978-3-319-16522-6_7

25. Ding B, Ling HW, Zhang Y, Huang J, Zhang H, Wang T, et al. Pattern of cerebral hyperperfusion in Alzheimer's disease and amnestic mild cognitive impairment using voxel-based analysis of 3D arterial spin-labeling imaging: initial experience. Clin Interv Aging (2014) 9:493-500. doi:10.2147/CIA. S58879 
26. Hu WT, Wang Z, Lee VM, Trojanowski JQ, Detre JA, Grossman M. Distinct cerebral perfusion patterns in FTLD and AD. Neurology (2010) 75:881-8. doi:10.1212/WNL.0b013e3181f11e35

27. Grasby PM, Frith CD, Paulesu E, Friston KJ, Frackowiak RS, Dolan RJ. The effect of the muscarinic antagonist scopolamine on regional cerebral blood flow during the performance of a memory task. Exp Brain Res (1995) 104:337-48. doi:10.1007/BF00242019

28. Honer WG, Prohovnik I, Smith G, Lucas LR. Scopolamine reduces frontal cortex perfusion. J Cereb Blood Flow Metab (1988) 8:635-41. doi:10.1038/ jcbfm.1988.110

29. Prohovnik I, Arnold SE, Smith G, Lucas LR. Physostigmine reversal of scopolamine-induced hypofrontality. J Cereb Blood Flow Metab (1997) 17:220-8. doi:10.1097/00004647-199702000-00012

30. Graef S, Schonknecht P, Sabri O, Hegerl U. Cholinergic receptor subtypes and their role in cognition, emotion, and vigilance control: an overview of preclinical and clinical findings. Psychopharmacology (Berl) (2011) 215:205-29. doi:10.1007/s00213-010-2153-8

31. Medeiros R, Kitazawa M, Caccamo A, Baglietto-Vargas D, EstradaHernandez T, Cribbs DH, et al. Loss of muscarinic M1 receptor exacerbates Alzheimer's disease-like pathology and cognitive decline. Am J Pathol (2011) 179:980-91. doi:10.1016/j.ajpath.2011.04.041

32. Jiang S, Li Y, Zhang C, Zhao Y, Bu G, Xu H, et al. M1 muscarinic acetylcholine receptor in Alzheimer's disease. Neurosci Bull (2014) 30:295-307. doi:10.1007/ s12264-013-1406-Z

33. Klinkenberg I, Blokland A. A comparison of scopolamine and biperiden as a rodent model for cholinergic cognitive impairment. Psychopharmacology (Berl) (2011) 215:549-66. doi:10.1007/s00213-011-2171-1

34. Witkin JM, Overshiner C, Li X, Catlow JT, Wishart GN, Schober DA, et al. $\mathrm{M} 1$ and $\mathrm{m} 2$ muscarinic receptor subtypes regulate antidepressant-like effects of the rapidly acting antidepressant scopolamine. J Pharmacol Exp Ther (2014) 351:448-56. doi:10.1124/jpet.114.216804

35. Sambeth A, Riedel WJ, Klinkenberg I, Kähkönen S, Blokland A. Biperiden selectively induces memory impairment in healthy volunteers: no interaction with citalopram. Psychopharmacology (Berl) (2015) 232:1887-97. doi:10.1007/ s00213-014-3822-9

36. Guthrie SK, Manzey L, Scott D, Giordani B, Tandon R. Comparison of central and peripheral pharmacologic effects of biperiden and trihexyphenidyl in human volunteers. J Clin Psychopharmacol (2000) 20:77-83. doi:10.1097/00004714-200002000-00013

37. Kuduk SD, Beshore DC. Novel M(1) allosteric ligands: a patent review. Expert Opin Ther Pat (2012) 22:1385-98. doi:10.1517/13543776.2012.731395

38. McArthur RA, Gray J, Schreiber R. Cognitive effects of muscarinic M1 functional agonists in non-human primates and clinical trials. Curr Opin Investig Drugs (2010) 11:740-60.

39. Melancon BJ, Tarr JC, Panarese JD, Wood MR, Lindsley CW. Allosteric modulation of the M1 muscarinic acetylcholine receptor: improving cognition and a potential treatment for schizophrenia and Alzheimer's disease. Drug Discov Today (2013) 18:1185-99. doi:10.1016/j.drudis.2013. 09.005

40. Bodick NC, Offen WW, Levey AI, Cutler NR, Gauthier SG, Satlin A, et al. Effects of xanomeline, a selective muscarinic receptor agonist, on cognitive function and behavioral symptoms in Alzheimer disease. Arch Neurol (1997) 54:465-73. doi:10.1001/archneur.1997.00550160091022
41. Shekhar A, Potter WZ, Lightfoot J, Lienemann J, Dubé S, Mallinckrodt C, et al. Selective muscarinic receptor agonist xanomeline as a novel treatment approach for schizophrenia. Am J Psychiatry (2008) 165:1033-9. doi:10.1176/ appi.ajp.2008.06091591

42. Vardigan JD, Cannon CE, Puri V, Dancho M, Koser A, Wittmann M, et al. Improved cognition without adverse effects: novel M1 muscarinic potentiator compares favorably to donepezil and xanomeline in rhesus monkey. Psychopharmacology (Berl) (2015) 232:1859-66. doi:10.1007/ s00213-014-3813-x

43. Nathan PJ, Watson J, Lund J, Davies CH, Peters G, Dodds CM, et al. The potent M1 receptor allosteric agonist GSK1034702 improves episodic memory in humans in the nicotine abstinence model of cognitive dysfunction. Int J Neuropsychopharmacol (2013) 16:721-31. doi:10.1017/S14611457 12000752

44. Doralp S, Leung LS. Cholinergic modulation of hippocampal CA1 basal-dendritic long-term potentiation. Neurobiol Learn Mem (2008) 90:382-8 doi:10.1016/j.nlm.2008.05.013

45. Dennis SH, Pasqui F, Colvin EM, Sanger H, Mogg AJ, Felder CC, et al. Activation of muscarinic M1 acetylcholine receptors induces long-term potentiation in the hippocampus. Cereb Cortex (2016) 26:414-26. doi:10.1093/cercor/ bhv227

46. Marino MJ, Rouse ST, Levey AI, Potter LT, Conn PJ. Activation of the genetically defined $\mathrm{m} 1 \mathrm{muscarinic}$ receptor potentiates $\mathrm{N}$-methyl-D-aspartate (NMDA) receptor currents in hippocampal pyramidal cells. Proc Natl Acad Sci U S A (1998) 95:11465-70. doi:10.1073/pnas.95.19.11465

47. Maltese M, Martella G, Madeo G, Fagiolo I, Tassone A, Ponterio G, et al. Anticholinergic drugs rescue synaptic plasticity in DYT1 dystonia: role of M1 muscarinic receptors. Mov Disord (2014) 29:1655-65. doi:10.1002/mds.26009

48. Tzavos A, Jih J, Ragozzino ME. Differential effects of M1 muscarinic receptor blockade and nicotinic receptor blockade in the dorsomedial striatum on response reversal learning. Behav Brain Res (2004) 154:245-53. doi:10.1016/j. bbr.2004.02.011

49. Shapovalova KB, Kamkina YV, Mysovskii DA. The effects of microinjection of the selective blocker of muscarinic M1 receptors pirenzepine into the neostriatum on the motor behavior of rats. Neurosci Behav Physiol (2005) 35:589-94. doi:10.1007/s11055-005-0098-x

50. Digby GJ, Noetzel MJ, Bubser M, Utley TJ, Walker AG, Byun NE, et al. Novel allosteric agonists of M1 muscarinic acetylcholine receptors induce brain region-specific responses that correspond with behavioral effects in animal models. J Neurosci (2012) 32:8532-44. doi:10.1523/JNEUROSCI.033712.2012

Conflict of Interest Statement: The authors declare that the research was conducted in the absence of any commercial or financial relationships that could be construed as a potential conflict of interest.

Copyright (C) 2016 Blokland, Sambeth, Prickaerts and Riedel. This is an open-access article distributed under the terms of the Creative Commons Attribution License (CC $B Y)$. The use, distribution or reproduction in other forums is permitted, provided the original author(s) or licensor are credited and that the original publication in this journal is cited, in accordance with accepted academic practice. No use, distribution or reproduction is permitted which does not comply with these terms. 